\title{
Pro-apoptotic Bax is the major and Bak an auxiliary effector in cytokine deprivation-induced mast cell apoptosis
}

\author{
M Karlberg ${ }^{1}$, M Ekoff ${ }^{1}$, V Labi ${ }^{2}$, A Strasser ${ }^{3}$, D Huang ${ }^{3}$ and G Nilsson ${ }^{\star, 1}$
}

The process of apoptosis in immune cells like mast cells is essential to regain homeostasis after an inflammatory response. The intrinsic pathway of apoptosis is ultimately controlled by the pro-apoptotic Bcl-2 family members Bax and Bak, which upon activation oligomerize to cause increased permeabilization of the mitochondria outer membrane leading to cell death. We examined the role of Bax and Bak in cytokine deprivation-induced apoptosis in mast cells using connective tissue-like mast cells and mucosal-like mast cells derived from $\mathrm{bax}^{-/-}, \mathrm{bak}^{-1-}$ and $\mathrm{bax}^{-/-} \mathrm{bak}^{-1-}$ mice. Although both Bax and Bak were expressed at readily detectable protein levels, we found a major role for Bax in mediating mast cell apoptosis induced by cytokine deprivation. We analyzed cell viability by propidium iodide exclusion and flow cytometry after deprivation of vital cytokines for each mast cell population. Upon cytokine withdrawal, bak ${ }^{-/}$mast cells died at a similar rate as wild type, whereas bax ${ }^{-l-}$ and $b a^{-I-} b a k^{-I-}$ mast cells were partially or completely resistant to apoptosis, respectively. The total resistance seen in bax ${ }^{-I-}$ bak $^{-I-}$ mast cells is comparable with mast cells deficient of both pro-apoptotic Bim and Puma or mast cells overexpressing anti-apoptotic Bcl-2. These results show that Bax has a predominant and Bak a minor role in cytokine deprivation-induced apoptosis in both connective tissue-like and mucosal-like mast cells.

Cell Death and Disease (2010) 1, e43; doi:10.1038/cddis.2010.20; published online 13 May 2010

Subject Category: Immunity

This is an open-access article distributed under the terms of the Creative Commons Attribution License, which permits distribution and reproduction in any medium, provided the original author and source are credited. This license does not permit commercial exploitation without specific permission.

Apoptosis is a genetically programmed mechanism for induction of cell death. During an allergic inflammation, the number of inflammatory immune cells including mast cells increase at site. During the resolution phase and termination of the inflammation, the process of apoptotic cell death is critical to regain cellular and tissue homeostasis. ${ }^{1}$

The intrinsic pathway of apoptosis is activated by stimuli such as growth factor deprivation or cell stress, including DNA damage $^{2}$ and is tightly regulated by interactions between pro- and anti-apoptotic members of the Bcl-2 family. The proapoptotic BH3-only proteins comprising Bim, Bad, Noxa and Puma are essential for initiation of apoptosis signaling. This group of proteins activates the pro-apoptotic effector proteins $\mathrm{Bax}$ and Bak indirectly by binding to the anti-apoptotic $\mathrm{Bcl}-2$ family members (Bcl-2, Bcl- $\mathrm{x}_{\mathrm{L}}, \mathrm{Bcl}-\mathrm{w}, \mathrm{Mcl}-1$ and $\left.\mathrm{Bfl}-1 / \mathrm{A} 1\right)$ and thereby titrate them away from Bax and Bak. ${ }^{3}$ Whether the activation of Bax and Bak occurs only indirectly is, however, actively debated. A model of direct binding and activation of Bax and Bak by the promiscuous BH3-only proteins Bid, Bim and possibly Puma has also been suggested. ${ }^{4-7}$ Activation of Bax and Bak causes permeabilization of the mitochondrial outer membrane, leading to release of cytochrome $c$, activation of caspase- 9 and ultimately cell demolition. ${ }^{8}$

Activation of mast cells by aggregation of the high affinity receptor for $\operatorname{lgE}, \mathrm{Fc} \varepsilon \mathrm{RI}$, is a key event in allergic reactions leading to degranulation and release of pro-inflammatory mediators. Connective tissue-like mast cells (CTLMC) but not mucosal-like mast cells (MLMC) withstand the degranulation process by activation-induced survival, ${ }^{9}$ a process in which the induction and function of the pro-survival protein $A 1$ is crucial. ${ }^{10}$ In addition, other Bcl-2 family members such as the pro-survival protein $\mathrm{Bcl}-\mathrm{X}_{\mathrm{L}}$ but also the pro-apoptotic protein Bim are upregulated by $\mathrm{Fc} \varepsilon \mathrm{RI}$ aggregation in mast cells. ${ }^{11}$

Experiments with gene-targeted mice have shown that loss of either $\mathrm{Bim}^{11}$ or Puma ${ }^{12}$ renders mast cells partially resistant to cytokine deprivation-induced apoptosis. Experiments using RNAi-mediated knockdown of gene expression showed that the pro-survival $\mathrm{Bcl}-2$ family member $\mathrm{Mcl}-1$ is critical for

\footnotetext{
${ }^{1}$ Department of Medicine, Karolinska Institutet, Stockholm, Sweden; ${ }^{2}$ Division of Developmental Immunology, Biocenter, Innsbruck Medical University, Innsbruck, Austria and ${ }^{3}$ The Walter and Eliza Hall Institute of Medical Research, Melbourne, Australia

${ }^{*}$ Corresponding author: G Nilsson, Department of Medicine, Karolinska Institutet, Clinical Immunology and Allergy Unit, KS L2:04, Stockholm 171 76, Sweden. Tel: + 4685177 0205; Fax: + 468335 724; E-mail: Gunnar.p.nilsson@ki.se

Keywords: Bcl-2; BH3-only; indirect apoptosis model

Abbreviations: Bcl-2, B-cell lymphoma-2; Bax, Bcl-2-associated X protein; Bak, Bcl-2 -antagonist/killer-1; BH3, Bcl-2 homology domain 3; Bim, Bcl-2-interacting mediator of cell death; Noxa, Latin for damage; Puma, p53 upregulated modulator of apoptosis; Bcl-XL, Bcl-2 like protein extra large; Bcl-w, Bcl-2 like 2; Mcl-1, myeloid cell leukemia sequence -1; Bfl-1/A1, Bcl-2 related protein A1; tBid, truncated BH3-interacting domain death agonist; CTLMC, connective tissue like mast cell; MLMC, mucosal like mast cell; FceRI, Fc epsilon receptor I; SCF, stem cell factor; MEF, mouse embryonic fibroblast; RPA, RNase protection assay; PI, propidium iodide Received 22.12.09; revised 24.3.10; accepted 07.4.10; Edited by D Bano
} 
sustained survival of transformed mast cells. ${ }^{13}$ In this study, we have examined the role of the two pro-apoptotic effector proteins Bax and Bak in mast cells, using cells deficient in Bax, Bak or both. We found that Bax has a more prominent role than Bak in cytokine deprivation-induced apoptosis in both CTLMC and MLMC.

\section{Results}

Characterization of in vitro-produced $\mathrm{bax}^{-/} \mathrm{bak}^{-/}$ MLMC and CTLMC. To characterize bax $^{-/-}$bak $^{-/-}$MLMC and CTLMC, we examined their surface expression of Kit and the high-affinity $\mathrm{IgE}$ receptor $\mathrm{F} \varepsilon \varepsilon \mathrm{RI}$. Immunofluorescent staining with specific Abs and flow cytometric analysis showed that mast cell populations lacking Bax and Bak expressed levels of Kit and $\mathrm{F}_{\mathrm{C} \varepsilon \mathrm{RI}}$ similar to their wt counterpart (Figure 1a). We then compared the response of wt and $\mathrm{bax}^{-/-} \mathrm{bak}^{-/-}$MLMC and CTLMC, respectively, to $\mathrm{Fc}_{\varepsilon} \mathrm{Rl}$ crosslinking measuring degranulation using a $\beta$-hexosaminidase assay. In response to $\mathrm{F} c \varepsilon \mathrm{RI}$ cross-linking both wt and bax $^{-1-}$ bak $^{-1-}$ MLMC and CTLMC, respectively, responded by degranulation to a similar magnitude (Figure 1b). These results show that the in vitro-produced cells resembled primary mast cells, as confirmed by toluidine blue staining of cytoplasmic granules (data not shown), expression of $\mathrm{Fc} \varepsilon \mathrm{RI}$ and $\mathrm{c}-\mathrm{Kit}$. In these respects, wt mast cells and mast cells lacking Bax and Bak were indistinguishable.
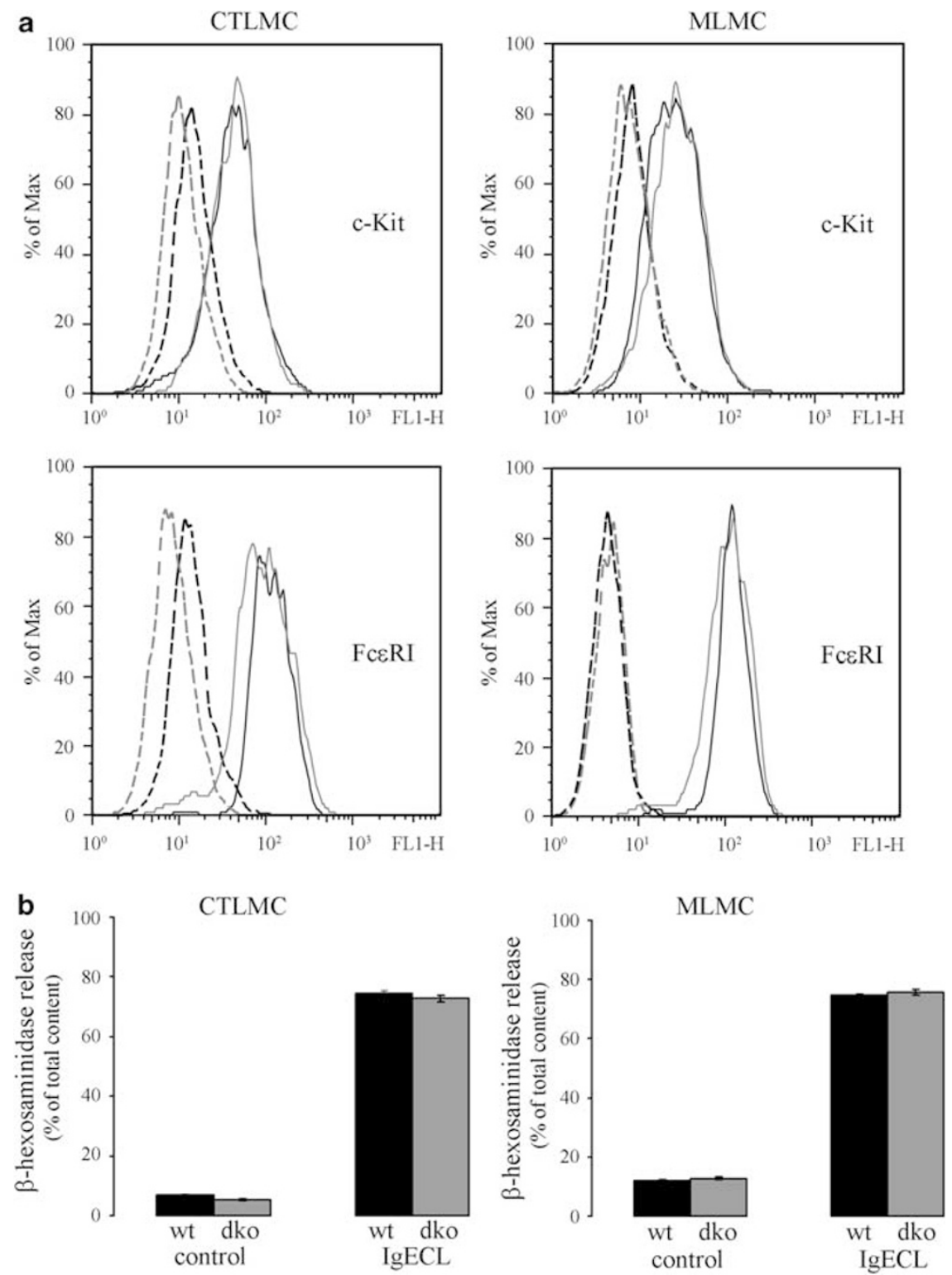

Figure 1 (a) Expression of the receptors Kit and Fc\&RI on the cell surface of wt and bax ${ }^{-/-}$bak ${ }^{-/-}$CTLMC and MLMC as examined by flow cytometry. The colors black and gray represents wt and $b_{a x}{ }^{-1-}$ bak ${ }^{-/-}$mast cells, respectively. A dashed line represents the staining with an isotype-matched control Ab, whereas the filled line represents staining with Abs for either Kit or Fc\&RI. $\beta$-hexosaminidase release upon $\mathrm{F} c \varepsilon R I$ cross-linking of wt and $b a x^{-/} b^{-1-}$ (dko) CTLMC and MLMC, respectively (b). One representative of two independent experiments is presented 


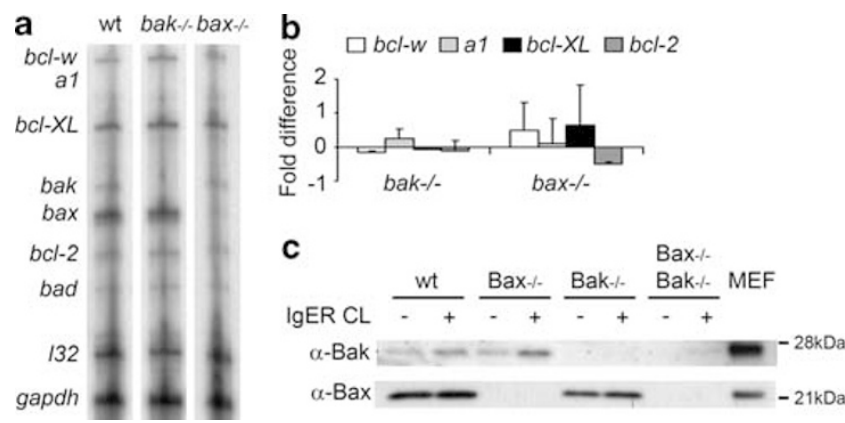

Figure 2 (a) Expression of mRNA for Bcl-2 members was analyzed using RPA. Extracted mRNA, $2 \mu \mathrm{g}$ per sample, was analyzed using a mAPO-2 multi-probe template according to the RiboQuant System protocol. Presented is one representative of two independent experiments. (b) The expression levels of prosurvival $b c /-2$ family members were quantified in relation to control 132 and gapdh using a phosphor-imager device. Data is presented as fold difference compared with wild type of two different sets of RPA. (c) Both Bax and Bak proteins are expressed in wt CTLMC and control cells, mouse embryonic fibroblasts (MEF). Mast cells were either resting or activated by IgE receptor cross-linking for $5 \mathrm{~h}$. One representative of three independent experiments is presented

Expression of Bax and Bak in mast cells. Mast cells were differentiated from mouse embryonic fetal livers. After 4 weeks in culture, pure cell cultures of CTLMC were obtained. We then started by examining the protein and mRNA expression of the two effector proteins Bax and Bak. Analyzing mRNA expression of Bax and Bak in CTLMC by RNase protection assay (RPA) revealed a more abundant expression of bax compared with bak (Figure 2a). Moreover, loss of either bax or bak did not cause any compensatory alteration in the expression of the pro-survival genes $b c l-w$, $a 1, b c l-x_{L}$ or $b c l-2$ (Figure $2 b$ ). On protein level, both Bax and Bak were detected in wild-type mast cells, although the levels of Bak appeared to be lower than the levels of Bax. Expectedly, no Bax or Bak protein was seen in mast cells from respectively knock-out as well as from double-deficient mast cells (Figure 2c). Furthermore, we investigated if activation of mast cells through $\mathrm{Fc \varepsilon RI}$ not only alters the expression of pro-survival proteins and BH3-only proteins, ${ }^{10,11}$ but also the effector proteins Bax and Bak. We could observe a minor upregulating effect on Bak but no prominent effect on Bax (Figure 2c), suggesting that IgE receptor activation primarily controls mast cell survival by regulating the levels and function of survival proteins and $\mathrm{BH} 3-$ only proteins and not the effector proteins.

Loss of Bax protects mast cells from cytokine deprivation-induced apoptosis. Although both Bax and Bak have been shown to have largely overlapping functions in several cell types (e.g., lymphoid cells ${ }^{14,15}$ ), it has also been reported that one of these proteins can have the dominant role. For example, Bax has the dominant role in programmed cell death during spermatogenesis ${ }^{16}$ and in NGF deprivation-induced killing of neuronal cells, ${ }^{17}$ whereas Bak is essential for cell death in platelets. ${ }^{18}$ To investigate whether both Bax and Bak are necessary for mast cell apoptosis we assessed cytokine deprivation-induced apoptosis in mast cells deficient in bax, bak or both $\left(\right.$ bax $^{-1-}$ bak $\left.^{-1-}\right)$ and wild type. After $36 \mathrm{~h}$ of starvation, more

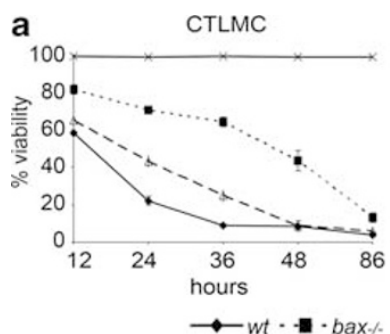

b

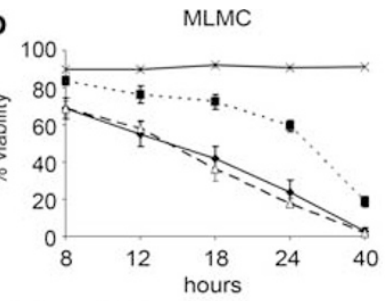

C
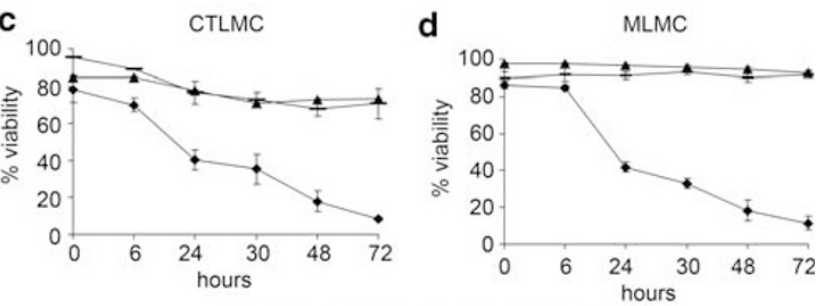

e

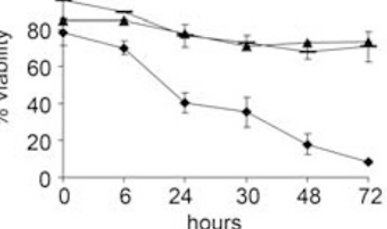

$\leftarrow$ - wt - vav-bcl-2 $\downarrow$ bim- puma

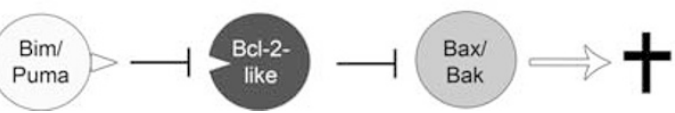

Figure 3 ( $\mathbf{a}$ and $\mathbf{b}$ ) Loss of Bax protects both CTLMC and MLMC from cytokine deprivation-induced apoptosis more potently than loss of Bak. Mast cells from wt,

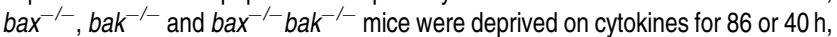
respectively. Cell viability was analyzed by PI staining and FACS analysis. Data are presented as mean ( \pm S.E.M.) of three independent experiments. (c and d) Survival of CTLMC and MLMC from wt, bim $^{-1}$ puma $^{-1}$ and vav-bcl-2 transgenic mice in absence of cytokines was also analyzed by PI staining and FACS analysis. Data are presented as mean $( \pm$ S.D.) of at least three independent experiments. (e) A schematic picture illustrating the model of indirect activation of apoptosis involving the three groups of $\mathrm{Bcl}-2$ family proteins controlling cell fate: proapoptotic BH3-only proteins (Bim and Puma), anti-apoptotic Bcl-2-like proteins ( $\mathrm{Bcl}$ 2) and effector proteins (Bax/Bak)

than $60 \%$ of $\mathrm{bax}^{-/-}$, but less than $25 \%$ of the $\mathrm{bak}^{-/-}$and wt CTLMC were viable. The same pattern was seen in MLMC although somewhat more rapid, with more than $60 \%$ viability of $\mathrm{bax}^{-/-}$mast cells and less than $25 \%$ of the bak $^{-1-}$ or wt already at $24 \mathrm{~h}$ (Figure $3 \mathrm{a}$ and $\mathrm{b}$ ). Notably, only combined loss of both Bax and Bak conferred complete resistance to cytokine deprivation, which demonstrates that Bak does have a role in mast cell apoptosis, albeit a lesser one compared with Bax.

\section{Discussion}

In the present study we have analyzed the individual and combined roles of Bax and Bak in cytokine deprivationinduced apoptosis in two mast cell sub-populations, MLMC and CTLMC. We show that Bax has a more prominent role in mast cell apoptosis than Bak, because mast cells lacking Bax have an increased and prolonged survival compared with Bak-deficient mast cells. However, only combined loss of both Bak and Bax conferred complete resistance to cytokine deprivation to a comparable extent as $\mathrm{Bcl}-2$ overexpression or combined loss of Puma and Bim (Figure $3 \mathrm{c}$ and $\mathrm{d}$ and Alfredsson et al. ${ }^{11}$ and Ekoff et al. ${ }^{12}$ ). This shows that Bak does have a function in mast cell apoptosis induced by cytokine deprivation, albeit a lesser one compared with Bax. Both Bax and Bak proteins are expressed in mast cells, 
however, the level of Bax is higher than Bak, which could be a plausible explanation for the increased survival in Baxdeficient mast cells when compared with those lacking Bak. In addition, the augmented survival of mast cells deficient in Bak may be an effect of redundancy between the two effector proteins.

MLMC and CTLMC overexpressing Bcl-2, or cells deficient in the two BH3-only proteins Bim and Puma, resemble Bak/Bax double-deficient mast cells in their profound resistance to cytokine deprivation-induced apoptosis. By affecting critical $\mathrm{Bcl}-2$ family proteins in each of the three levels of the model of indirect activation of apoptosis (Figure 3 and Willis et al. ${ }^{3}$, Chen et al. ${ }^{19}$ and Willis et al. ${ }^{20}$ ) cytokine deprivation-induced apoptosis in mast cells can be inhibited. According to this model, pro-apoptotic BH3-only proteins activate Bak and Bax only by neutralizing pro-survival proteins such as $\mathrm{Bcl}-2$, and not by direct interaction between Bak/Bax and the $\mathrm{BH}$-only proteins (Figure $3 e$ ). Our previous findings together with the data presented here indicate that the two BH3-only proteins Bim and Puma are essential for cytokine deprivation-induced apoptosis in mast cells and that Bim and Puma together interact with and neutralize all pro-survival proteins involved. Furthermore, overexpressing $\mathrm{Bcl}-2$ in mast cells is sufficient for profound resistance to cytokine deprivation-induced apoptosis, suggesting that $\mathrm{Bcl}-2$ keeps both effector proteins in check. In mouse embryo fibroblasts, Bak is restrained by the pro-survival proteins $\mathrm{Mcl}-1$ and $\mathrm{Bcl}-\mathrm{x}_{\mathrm{L}}$, but not $\mathrm{Bcl}-2,{ }^{20}$ whereas $\mathrm{Bax}$ is probably inhibited by the pro-survival proteins $\mathrm{Bcl}-2$, Bcl-w, Bcl- $\mathrm{x}_{\mathrm{L}}$ and $\mathrm{Mcl}-1 .^{3}$ Our data about Bax having a more prominent role compared with Bak in cytokine deprivation-induced apoptosis in mast cells might conduce to explain why mast cells overexpressing $\mathrm{Bcl}-2$ are totally resistant to apoptosis.

The data presented here are in accordance with a previous report in which IL-3 derived bone marrow mast cells from bax $^{-/-}$mice were shown to have an increased survival upon cytokine deprivation. ${ }^{21}$ They also found an increase in mast cell numbers in the stomach mucosa and a minor increase of mast cells in back skin of $b^{-/-}$mice compared with wild-type mice. This indicates that for mast cell homeostasis, Bax has a more prominent role in mucosal mast cells compared with connective tissue mast cells. By contrast, our in vitro data reveal no difference in the importance of Bax for the induction of apoptosis in MLMC and CTLMC, suggesting other additional mechanisms in vivo.

Mast cells are implicated in a number of different diseases where reducing their numbers would be beneficial for reducing the severity of the symptoms, and in the best scenario contribute to cure the disease. These diseases include mast cell-driven diseases like mastocytosis ${ }^{22}$ and allergic reactions, but also chronic inflammations such as atherosclerosis and autoimmune diseases ${ }^{23-25}$ and tumors. ${ }^{26}$

In summary, in this paper we have analyzed the roles of the two pro-apoptotic proteins Bak and Bax in cytokine deprivation-induced apoptosis of CTLMC and MLMC. We report that Bax has a more prominent role than Bak in this process; however, both are needed because only $\mathrm{bax}^{-/} \mathrm{bak}^{-/}$cells were totally resistant to cytokine deprivation-induced apoptosis. Our results contribute to the work of deciphering the role of the $\mathrm{Bcl}-2$ family members in the regulation of mast cell survival and apoptosis and have implications for designing new therapeutic protocols for treatment of mast cell-associated disorders.

\section{Materials and Methods}

Mice and cell cultures. The generation and genotyping of $b a x^{-/-}, b a k^{-/-}$, bax $^{-1-}$ bak $^{-1-}$ and bim $^{-1-}$ puma ${ }^{-1-}$ as well as vav-bcl-2-transgenic mice have been described previously. ${ }^{14,16}$ Fetal liver-derived mast cells from wt C57BL/6 mice or mice of bax ${ }^{-1-}$, bak ${ }^{-/-}$and $b a x^{-1-}$ bak $^{-/-}$were differentiated into CTLMC or MLMC using previously described protocols. ${ }^{9}$ Briefly, fetal livers from E14 mouse embryos were dissected and kept on ice in KDS BSS $+10 \%$ FBS. Livers were homogenized, cells washed in PBS and cultured at $3 \times 10^{5}$ cells per ml under conditions promoting the development of CTLMC (RPMI-1640 supplemented with $25 \mathrm{ng} / \mathrm{ml} \mathrm{rSCF}$ and $1 \mathrm{ng} / \mathrm{ml} \mathrm{rlL-4}$ (Peprotech EC Ltd, Rocky Hill, NJ, USA)) or MLMC (DMEM supplemented with $25 \mathrm{ng} / \mathrm{ml}$ rSCF, $100 \mathrm{U} / \mathrm{ml} \mathrm{IL-3} \mathrm{(cell} \mathrm{supernatant} \mathrm{from}$ X63/0 hybridoma stably transfected with an IL-3 expression vector), $5 \mathrm{ng} / \mathrm{ml} \mathrm{rlL}-9$ and $1 \mathrm{ng} / \mathrm{ml}$ rTGF- $\beta_{1}$ (both from R\&D systems, Minneapolis, MN, USA)) respectively. All cells were cultured 4 weeks before being used. Similarly, bone marrow cells from wild type, vav-bcl-2-transgenic and bim $^{-1-}$ puma $^{-1-}$ were differentiated into CTLMC and MLMC using protocols described. ${ }^{9}$ All experiments with animals were performed according to the guidelines of the Royal Melbourne Hospital Research Foundation Animal Ethics Committee or the Animal Ethics Committee in Stockholm.

Detection of Kit and Fc\&RI on mast cell surface. The cells were examined by flow cytometric analysis for expression of Kit and Fc $\varepsilon$ RI, using FITCanti-mouse CD117 (Kit) mAb 2B8 or FITC-conjugated rat IgG2b isotype control (both from BD Pharmingen, San Diego, CA, USA), FITC-conjugated anti-mouse FceRI mAb MAR-1, or FITC-conjugated Armenian hamster IgG isotype control (both from eBioscience, Hatfield, UK).

In vitro cell activation by IgE receptor crosslinking. CTLMCs and MLMCs were suspended at $5 \times 10^{5}$ cells per $\mathrm{ml}$. For Fc\&Rl stimulation, mast cells were sensitized for 90 min using a monoclonal murine lgE anti-TNP antibody (IgE1-b4, ATCC), supplied as a $15 \%$ hybridoma supernatant. The cells were washed twice in PBS and then challenged with $10 \mathrm{ng} / \mathrm{ml}$ TNP-BSA (coupling ratio 9, Biosearch Technologies Inc, San Francisco, CA, USA) for the time periods indicated. Cell viability was determined by propidium iodide exclusion $(5 \mu \mathrm{g} / \mathrm{ml}$, Sigma-Aldrich, Steinheim, Germany) and flow cytometric analysis using a FACScan (Becton Dickinson, Franklin Lakes, NJ, USA). ${ }^{9}$

$N$-acetyl- $\beta$-D-hexosaminidase release assay. Cells to be used in the $N$-acetyl- $\beta$-D-hexosaminidase assay were resuspended in RPMI 1640 medium supplemented with $0.2 \%$ BSA (Sigma-Aldrich) before the cells were activated by lgE receptor crosslinking. For detection of the granular enzyme $\beta$-hexosaminidase, an enzymatic colorimetric assay was used as described previously. ${ }^{10}$ Briefly, $60 \mu \mathrm{l}$ of supernatant was transferred to a 96-well plate and mixed with an equal volume of substrate solution ( $7.5 \mathrm{mM} p$-nitrophenyl- $N$-acetyl- $\beta$-D-glucosaminide dissolved in $80 \mathrm{mM}$ citric acid, $\mathrm{pH}$ 4.5). The mixture was incubated on a rocker platform for $2 \mathrm{~h}$ at $37^{\circ} \mathrm{C}$. After incubation, $120 \mu$ l of glycine $(0.2 \mathrm{M}, \mathrm{pH} 10.7)$ was added to each well, and the absorbance at 405 and $490 \mathrm{~nm}$ was measured using an Emax Precision Microplate Reader (Molecular Devices, Sunnyvale, CA, USA).

Western blot analysis. CTLMCs $\left(1.5 \times 10^{6}\right.$ cells $)$ were activated by lgE receptor cross-linking and harvested after $5 \mathrm{~h}$, washed in ice-cold PBS, and lysed in RIPA buffer ( $50 \mathrm{mM}$ Tris-HCl pH 7.4, $150 \mathrm{mM} \mathrm{NaCl}, 1 \% \mathrm{NP}-40,0.5 \%$ Sodium deoxycholate, $0.1 \%$ SDS) supplemented with protease inhibitors (Roche, Mannheim, Germany). Lysates from mouse embryonic fibroblasts (MEF) were included as control for expression of Bax and Bak. Protein, $40 \mu \mathrm{g}$, was dissolved in SDS loading buffer and size-fractionated on 12\% Tris-glycine gels (Invitrogen, Carlsbad, CA, USA). Western blotting was performed using polyclonal rabbit antiBak antibodies (1:1000; Sigma-Aldrich) or a monoclonal mouse anti-Bax antibody (1:1000; Sigma-Aldrich), followed by horseradish peroxidase-conjugated sheep anti-rabbit IgG or sheep anti-mouse IgG antibodies (1:5000; Chemicon, Temecula, CA, USA). Bound antibodies were visualized by enhanced chemoluminoscence $(E C L)$ and exposure to Hybond ECL film (Amersham Biosciences, Uppsala, Sweden). 
RNase protection assay. Total RNA was extracted using TriPure isolation reagent (Roche). mRNA, $2 \mu \mathrm{g}$ per sample was analyzed by RPA according to the RiboQuant System (Becton Dickinson) protocol, using a mAPO-2 multi-probe template (Becton Dickinson). The gel was dried and exposed on Kodak film (Eastman Kodak Company, Stockholm, Sweden) with intensifying screens at $-70^{\circ} \mathrm{C}$. Quantification was performed using a phospho-imager device and MacBas V2.2 Software (Fuji Photo Film, Co. Ltd., Stockholm, Sweden).

\section{Conflict of interest}

The authors declare no conflict of interest.

Acknowledgements. We thank Dr. Craig Thompson for providing the bak ${ }^{-1-}$ mice and Dr. H Martin and P Morgan for stem cell factor. This work was supported by fellowships and grants from the Erik and Edith Fernströms foundation for Medical Research, Karolinska Institutet, the Centre for Allergy Research at Karolinska Institutet, the Swedish Research Council-Medicine, the Swedish Cancer Foundation, Ellen, Walter and Lennart Hesselmans foundation for scientific research, Ollie and Elof Ericsson's foundation, King Gustav V's 80-years foundation (all above MK, ME, GN), UICC International Cancer Technology Transfer (No:ICR/ 04/172) (ME), Tyrolean Science Fund (TWF) (VL), National Health and Medical Research Council (Australia; program no. 257502), the Cancer Council of Victoria, the Leukemia and Lymphoma Society (New York; SCOR Grant no. 7015) and the National Cancer Institute (NIH, US; CA 80188 and CA 43540) (AS, DH).

1. Serhan CN, Savill J. Resolution of inflammation: the beginning programs the end. Nat Immunol 2005; 6: 1191-1197.

2. Zhivotovsky B, Kroemer G. Apoptosis and genomic instability. Nat Rev Mol Cell Biol 2004; 5: 752-762.

3. Willis SN, Fletcher JI, Kaufmann T, van Delft MF, Chen L, Czabotar PE et al. Apoptosis initiated when $\mathrm{BH} 3$ ligands engage multiple Bcl-2 homologs, not Bax or Bak. Science 2007; 315: 856-859.

4. Cartron PF, Gallenne T, Bougras G, Gautier F, Manero F, Vusio P et al. The first alpha helix of Bax plays a necessary role in its ligand-induced activation by the BH3-only proteins Bid and PUMA. Mol Cell 2004; 16: 807-818.

5. Gavathiotis E, Suzuki M, Davis ML, Pitter K, Bird GH, Katz SG et al. BAX activation is initiated at a novel interaction site. Nature 2008; 455: 1076-1081.

6. Kim H, Rafiuddin-Shah M, Tu HC, Jeffers JR, Zambetti GP, Hsieh JJ, Cheng EH. Hierarchical regulation of mitochondrion-dependent apoptosis by BCL-2 subfamilies. Nat Cell Biol 2006; 8: 1348-1358.

7. Walensky LD, Pitter K, Morash J, Oh KJ, Barbuto S, Fisher J et al. A stapled BID BH3 helix directly binds and activates BAX. Mol Cell 2006; 24: 199-210.

8. Newmeyer DD, Ferguson-Miller S. Mitochondria: releasing power for life and unleashing the machineries of death. Cell 2003; 112: 481-490.

9. Ekoff M, Strasser A, Nilsson G. FcepsilonRI aggregation promotes survival of connective tissue-like mast cells but not mucosal-like mast cells. J Immunol 2007; 178: 4177-4183.
10. Xiang Z, Ahmed AA, Möller C, Nakayama K-i, Hatakeyama S, Nilsson G. Essential role of the pro-survival bc-2 homolog $A 1$ in mast cell survival following allergic activation. $J$ Exp Med 2001; 194: 1561-1569.

11. Alfredsson J, Puthalakath $\mathrm{H}$, Martin $\mathrm{H}$, Strasser A, Nilsson G. Proapoptotic Bcl-2 family member Bim is involved in the control of mast cell survival and is induced together with Bcl-XL upon IgE-receptor activation. Cell Death Differ 2005; 12: 136-144.

12. Ekoff M, Kaufmann T, Engstrom M, Motoyama N, Villunger A, Jonsson Jl et al. The $\mathrm{BH} 3-$ only protein Puma plays an essential role in cytokine deprivation-induced apoptosis of mast cells. Blood 2007; 110: 3209-3217.

13. Aichberger KJ, Mayerhofer M, Gleixner KV, Krauth MT, Gruze A, Pickl WF et al. Identification of MCL1 as a novel target in neoplastic mast cells in systemic mastocytosis: inhibition of mast cell survival by MCL1 antisense oligonucleotides and synergism with PKC412. Blood 2007; 109: 3031-3041.

14. Lindsten T, Ross AJ, King A, Zong WX, Rathmell JC, Shiels HA et al. The combined functions of proapoptotic Bcl-2 family members bak and bax are essential for normal development of multiple tissues. Mol Cell 2000; 6: 1389-1399.

15. Rathmell JC, Lindsten T, Zong WX. Cinalli RM, Thompson CB. Deficiency in Bak and Bax perturbs thymic selection and lymphoid homeostasis. Nat Immunol 2002; 3: 932-939.

16. Knudson CM, Tung KS, Tourtellotte WG, Brown GA, Korsmeyer SJ. Bax-deficient mice with lymphoid hyperplasia and male germ cell death. Science 1995; 270: 96-99.

17. Putcha GV, Deshmukh M, Johnson Jr EM. BAX translocation is a critical event in neuronal apoptosis: regulation by neuroprotectants, BCL-2, and caspases. J Neurosci 1999; 19: 7476-7485

18. Mason KD, Carpinelli MR, Fletcher JI, Collinge JE, Hilton AA, Ellis S et al. Programmed anuclear cell death delimits platelet life span. Cell 2007; 128: 1173-1186.

19. Chen L, Willis SN, Wei A, Smith BJ, Fletcher Jl, Hinds MG et al. Differential targeting of prosurvival $\mathrm{Bcl}-2$ proteins by their $\mathrm{BH} 3$-only ligands allows complementary apoptotic function. Mol Cell 2005; 17: 393-403.

20. Willis SN, Chen L, Dewson G, Wei A, Naik E, Fletcher Jl et al. Proapoptotic Bak is sequestered by $\mathrm{Mcl}-1$ and $\mathrm{Bcl}-\mathrm{xL}$, but not $\mathrm{Bcl}-2$, until displaced by $\mathrm{BH} 3-$ only proteins. Genes Dev 2005; 19: 1294-1305.

21. Maurer M, Tsai M, Metz M, Fish S, Korsmeyer SJ, Galli SJ. A role for Bax in the regulation of apoptosis in mouse mast cells. J Invest Dermatol 2000; 114: 1205-1206.

22. Metcalfe DD. Mast cells and mastocytosis. Blood 2008; 112: 946-956.

23. Leslie M. Mast cells show their might. Science 2007; 317: 614-616.

24. Benoist C, Mathis D. Mast cells in autoimmune disease. Nature 2002; 420: 875-878.

25. Sun J, Sukhova GK, Wolters PJ, Yang M, Kitamoto S, Libby P et al. Mast cells promote atherosclerosis by releasing proinflammatory cytokines. Nat Med 2007; 13: 719-724.

26. Soucek L, Lawlor ER, Soto D, Shchors K, Swigart LB, Evan GI. Mast cells are required for angiogenesis and macroscopic expansion of Myc-induced pancreatic islet tumors. Nat Med 2007; 13: 1211-1218.

Cell Death and Disease is an open-access journal published by Nature Publishing Group. This article is licensed under a Creative Commons Attribution-Noncommercial-No Derivative Works 3.0 License. To view a copy of this license, visit http:// creativecommons.org/licenses/by-nc-nd/3.0/ 